\title{
Saúde LGBTQIA+: a vulnerabilidade das minorias sexuais
}

\author{
LGBTQIA+ health: the vulnerability of sexual minorities \\ LGBTQIA+ salud: la vulnerabilidad de las minorias sexuales
}

Recebido: 29/09/2021 | Revisado: 08/10/2021 | Aceito: 10/10/2021 | Publicado: 12/10/2021

\author{
Fernando Barros de Sousa \\ ORCID: https://orcid.org/0000-0001-5935-0265 \\ Faculdade Integrada Carajás, Brasil \\ E-mail: fernandomaria1999@gmail.com \\ Patrícia Maria Lima Silva de Sousa \\ ORCID: https://orcid.org/0000-0002-2985-5163 \\ Faculdade Integrada Carajás, Brasil \\ E-mail: patriciasousa50anos@gmail.com
}

\begin{abstract}
Resumo
A saúde sempre foi uma questão essencial para que o ser humano pudesse realizar desde suas tarefas diárias até o cumprimento de realizações pessoais como desejos, objetivos e sonhos. Afinal sem saúde nada disso seria possível, por meio disso entende-se que todas as pessoas, sem exceção tem direito a tal. Mas ainda existem grupos marginalizados que tem direitos básicos negados seja de forma direta ou indiretamente. Surge então a necessidade de enunciar esse tema para que seja possível uma contribuição totalmente positiva aos leitores atingidos por essa revisão. O objetivo do estudo é dissertar sobre a saúde LGBTQIA+ e identificar pontos de melhoria para realização de um cuidado integral a esse grupo através da Política Nacional de Saúde Integral de Lésbicas, Gays, Bissexuais, Transexuais e Travestis (PNSILGBT) e demais programas que abrangem esses clientes em especial. Abordando a contribuição fundamental da enfermagem em todo o processo de atendimento: primário, secundário e terciário que corresponde pelas Unidades Básicas de Saúde (UBSs), as Unidades de Pronto Atendimento (UPAs), e os hospitais, respectivamente. Trata-se de uma revisão bibliográfica integrativa, realizada por meio de pesquisa em revistas eletrônicas, livros e a legislação pertinente a temática.
\end{abstract}

Palavras-chave: Saúde LGBTQIA+; Humanização; Minorias sexuais; Violência; Enfermagem.

\begin{abstract}
Health has always been an essential issue for human beings to carry out from their daily tasks to the fulfillment of personal achievements such as desires, goals and dreams. After all, without health, none of this would be possible, through this it is understood that all people, without exception, have the right to do so. But there are still marginalized groups that have basic rights denied either directly or indirectly. Then comes the need to enunciate this theme so that it is possible to make a totally positive contribution to the readers affected by this review. The objective of the study is to discuss LGBTQIA+ health and identify points of improvement for providing comprehensive care to this group through the National Policy on Comprehensive Health for Lesbians, Gays, Bisexuals, Transsexuals and Transvestites (PNSILGBT) and other programs that cover these customers in particular. Addressing the fundamental contribution of nursing throughout the care process: primary, secondary and tertiary, which corresponds to Basic Health Units (UBSs), Emergency Care Units (UPAs), and hospitals, respectively. This is an integrative bibliographic review, carried out through research in electronic journals, books and legislation relevant to the subject.
\end{abstract}

Keywords: LGBTQIA+ Health; Humanization; Sexual minorities; Violence; Nursing.

\section{Resumen}

La salud siempre ha sido un tema fundamental para que el ser humano lleve a cabo desde sus quehaceres diarios hasta la realización de logros personales como deseos, metas y sueños. Después de todo, sin salud, nada de esto sería posible, a través de esto se entiende que todas las personas, sin excepción, tienen derecho a hacerlo. Pero todavía hay grupos marginados a los que se les niegan los derechos básicos, ya sea directa o indirectamente. Luego surge la necesidad de enunciar este tema para que sea posible hacer un aporte totalmente positivo a los lectores afectados por esta revisión. El objetivo del estudio es discutir la salud LGBTQIA + e identificar puntos de mejora para brindar atención integral a este colectivo a través de la Política Nacional de Salud Integral para Lesbianas, Gays, Bisexuales, Transexuales y Travestis (PNSILGBT) y otros programas que cubren a estos clientes en especial. Abordar el aporte fundamental de la enfermería en todo el proceso asistencial: primario, secundario y terciario, que corresponde a Unidades Básicas de Salud (UBS), Unidades de Atención de Emergencias (UPA) y hospitales, respectivamente. Se trata de una revisión bibliográfica integradora, realizada a través de la investigación en revistas electrónicas, libros y legislación relevante en la materia.

Palabras clave: Salud LGBTQIA +; Humanización; Minorías sexuales; Violencia; Enfermería. 


\section{Introdução}

O tema vem para quebrar tabus, descontruir mentalidades retrógradas e de forma leve instruir e ensinar mais sobre uma população que merece ser tratada com humanidade e respeito. Algo que por mais que seja dito atualmente, faz-se, ainda, necessário estudos e abordagens mediante ao mesmo para o preparo e melhoria de qualificação da equipe multidisciplinar no atendimento em todos os níveis de atenção.

Este trabalho trata-se de uma revisão da literatura. Nasce através da necessidade de expor um assunto que tem baixa popularidade em meio a sociedade, e consequentemente entre os profissionais de saúde. Tem como intuito principal ser benéfico aos clientes que fazem parte de uma comunidade específica, intitulada "LGBTQIA+" um grupo, ainda, vulnerável por alguns fatores determinantes, tais como violência, preconceito e exclusão.

A revisão não trata as questões de vida deles com dramatização, mas sim utilizando de uma visão mais holística. Afinal entende-se que boa parte desse grupo, sofre alguns agravantes, sejam eles no meio social ou principalmente em seus lares. De acordo com ARÁN, (2009) a restrita experiência dos serviços de saúde que lidam com a transexualidade feminina, por exemplo, fazem com que essa situação leve a desordens psicológicas. Infelizmente soa como arcaico, porém reflete uma realidade atual.

Os principais transtornos e distúrbios aos quais são acometidos são de cúbito mental, tais como: ansiedade, depressão, crise de pânico e na pior das hipóteses comportamentos suicidas. Desta forma os serviços de saúde são primordiais, seja desde a atenção primária ao cuidado com a população LGBTQIA+, a qual é a porta de entrada aos serviços de saúde, onde terão a oportunidade de fazer parte dos programas que o SUS tem a lhes oferecer até a atenção terciária, com procedimentos de média e alta complexidade.

Sabe-se que é necessário bem-estar BIOPSICOSSOCIAL, que o ser humano necessita para que tenha qualidade de vida e quando se trata do público LGBTQIA+, essa realidade pode ser inexistente, desta forma é possível que a Enfermagem possa contribuir para a melhoria desse quadro. De forma fidedigna vem como uma profissão voltada à arte de cuidar, realizando abordagem das pessoas que necessitam de conforto, bem-estar, atenção, alívio dos sofrimentos e cuidado como declara a Dra. Ferreira (Ferreira, 2011).

É inquestionável a importância dessa profissão em medidas estratégicas para que o paciente obtenha melhor qualidade de vida em variados sentidos e aspectos, assim como o profissional terá consigo um sentimento de dever cumprido, de assistência prestada com êxito e isso refletirá em sua vida de forma positiva. Lembrando que essa luta é de toda uma população que busca por direitos e o mais essencial, respeito.

O ser humano está em constante evolução, em diversos aspectos da vida. A busca por ser diariamente melhor é um fato verídico. Com o acesso facilitado a informação tornar-se um ser evoluído tem se tornado cada dia mais próximo, um novo passo para melhorar no quesito relacionar-se com o "diferente" que na realidade é mais comum do que se imagina. Contudo, as coisas caminham para um lado positivo se comparado com a antiguidade.

\section{Metodologia}

\subsection{Tipo de estudo}

Tendo como autor que fornece suporte metodológico ao presente estudo, apresento SILVA, et al. (2020), que discorre sobre a (PNSI LGBT). O estudo consistirá em uma revisão da literatura sobre o tema e seus derivados em artigos acadêmicos que estão disponíveis na internet, meio esse utilizado como um instrumento de pesquisa técnico-científico. Reunindo os dados e colocando-os em pauta, levantando questionamentos a partir das fontes de consulta e listando os principais fatores que predispõe a população LGBTQIA+ a ser, ainda, atualmente vulneráveis. Para que dessa forma, possa haver atitude por parte das equipes de saúde, em especifico a Enfermagem, no cuidado e prevenção de doenças e agravos à saúde desse público, e ainda, demonstrar 
a necessidade de atualização da equipe multidisciplinar que tem contato direto ou indireto com esse cliente inerente, pois existe uma especificidade para cada público, e saber lidar, criar vínculo é de suma importância para um atendimento com excelência.

\subsection{Coleta de dados}

A busca foi realizada através de base de dados eletrônicos, tais como Scientific Eletronic Library Online (SciELO), WORLD HEALTH ORGANIZATION (WHO), Google Acadêmico, e o site official do Ministério da Saúde do Brasil também foi utilizado. Para o levantamento de dados sobre o assunto foram utilizados os descritores: "Saúde LGBTQIA+", "Minorias Sexuais", "Violência LGBTQIA+". No desenvolvimento do presente suposto, foram separadas em três etapas: primeiramente realizando uma busca pelo descritor "Saúde LGBTQIA+", segundo com o descritor "Minorias Sexuais" e a terceira e última etapa por meio do descritor "Violência LGBTQIA+".

\subsection{Critérios de inclusão e exclusão dos artigos}

Os critérios de inclusão foram basicamente: ser artigo original contendo textos completos para melhor entendimento e veracidade dos fatos apresentados, nos idiomas português e inglês; publicados desde 2008, que apesar de antigo apresenta uma relevância significativa para o embasamento da revisão até publicações do ano de 2020, que se fazem mais atuas. Os critérios de exclusão foram de artigos que não tinham compatibilidade com a temática aqui exposta.

Após realizar a pré-leitura dos artigos filtrados e selecionados com base nos critérios de inclusão e seleção, restaram 7 (sete) artigos que subsidiam a presente pesquisa. A busca teve início no mês de março de 2021, inicialmente 20 artigos foram escolhidos e através de um critério próprio de inclusão e exclusão restaram 7 artigos.

\section{Resultados e Discussão}

\subsection{Compreendendo a sigla LGBTQIA+}

L: lésbicas - É uma orientação sexual, onde mulheres (cisgênero ou transgênero) sentem-se atraídas de forma afetiva e sexualmente por outras mulheres (cisgênero ou transgênero).

G: gays - É uma orientação sexual, onde homens (cisgênero ou transgênero) sentem-se atraídos por outros homens (cisgênero ou transgênero).

B: bissexuais - É uma orientação sexual, onde pessoas se relacionam afetiva e sexualmente com homens e mulheres (incluindo homens e mulheres transgênero).

T: transexuais ou travestis - É um conceito relacionado à identidade de gênero. Não se identificam com o gênero biológico, ou seja, com o corpo e em alguns casos incluem os órgãos genitais.

Q: queer - Em inglês, pode ser traduzido como "estranho", é usado para designar as pessoas que se identificam como sendo de um terceiro gênero, fluido/andrógino, com característica masculinas e femininas.

I: intersexo - Descreve pessoas que podem nascer com genitais correspondentes a um sexo, mas ter o sistema reprodutivo e os hormônios do outro. Ou podem apresentar uma anatomia sexual que não é nem masculina nem feminina — o que leva alguns intersexos a fazer a cirurgia de redesignação sexual. No passado, essas pessoas eram chamadas erroneamente de hermafroditas, termo que não é mais socialmente aceito.

A: assexual - São as pessoas que não sentem atração sexual, seja pelo sexo oposto ou pelo mesmo sexo — o que não significa que não possam desenvolver sentimentos amorosos e afetivos por outras pessoas.

+: demais orientações sexuais e identidades de gênero

Pansexualidade: orientação sexual que significa que podem desenvolver atração física, amor e desejo sexual por outras pessoas independentemente de sua identidade de gênero ou sexo biológico. 
Não-binaridade: uma pessoa não-binária não se sente em conformidade com o sistema binário homem/mulher.

Crossdresser: homens cisgêneros que sentem prazer ao se vestirem como mulheres, mas não se consideram travestis.

\subsection{Violência com A população LGBTQIA+}

Deve ser levado em consideração as altas taxas de violência para com essa população. De acordo com o relatório “World Statistics 2019”, publicado pela Organização Mundial da Saúde (OMS) tendo como estimativa o ano de 2016, houve 477.000 homicídios em todo o mundo. Sendo que o Brasil apresentou cerca de 12,8\% do total mundial, o que representa a sétima maior taxa de homicídio do continente americano.

Segundo o Grupo Gay da Bahia (GGB, 2018), o Brasil "é o país com a maior quantidade de registros de crimes letais contra LGBT do mundo". Em 2018, registrou que 420 LGBT tiveram mortes violentas no Brasil, ou seja, a cada 20 horas é assassinado um indivíduo LGBT. Números que são alarmantes e assustam, e infelizmente tornam-se crescentes a cada dia que passa. Por isso faz-se importante ser um assunto a ser tratado com seriedade e urgência pelas autoridades competentes e subjacentes.

Da forma que é possível os movimentos estão sempre envolvidos levantando uma bandeira que por vezes taxada de vitimista, dramática e que as pessoas que estão inseridas na comunidade na realidade querem atenção voltadas a elas, como forma de querer aparecer grosso modo dizendo. $\mathrm{O}$ que na dura realidade dessas pessoas não é bem assim. Só quem vive na pele o preconceito, violência e discriminação de toda uma sociedade é que tem lugar de fala para expor todas as barbaridades que vivencia diariamente.

Violência ao qual esse público está exposto diariamente, que ao sair de casa se depara com diversas barreiras sociais impostas pelos indivíduos ao seu redor, que vem desde olhares no ponto de ônibus a comentários preconceituosos e desnecessários no ambiente de trabalho. Quando não se trata de algo muito mais extremo, como ataques violentos na rua, que resultam muitas vezes em algo fatal, e muitos vem a óbito. Quando não, ficam com traumas e cicatrizes para o resto de suas vidas.

Ser uma pessoa LGBTQIA+ no Brasil é um ato diário de resistência, de luta e busca por direitos, por voz e igualdade. Isso quando a pessoa não está relacionada a mais um fator, como por exemplo ser LGBT e negro. O que acarreta um peso ainda maior, como sendo um peso histórico e cultural.

Pelo fato de existir um padrão heteronormativo, atrelado ao preconceito vigente na sociedade atual faz com que pessoas sofram muita represália e com a pandemia da COVID-19 isso se tornou ainda mais evidente segundo evidências de estudos Fragoso, et al. (2021). Afinal, durante esse período foram adotadas diversas medidas para conter a propagação do vírus, sendo uma delas o isolamento social, o que fez com que as pessoas ficassem longos períodos dentro de suas residências. E com isso, entende-se que o grupo ao qual este trabalho se refere sofreu com alguns quesitos em suas relações pessoais e familiares devido a pandemia.

Através da revisão realizada por Barros e Coelho (2021), é possível compreender um pouco mais sobre as vivências de um público e alimentar-se de conhecimento sobre variados tópicos de suma importância para a sociedade atual e consequentemente a sociedade que está em formação. Afinal torna-se indispensável a contribuição do hoje para os homens de amanhã.

\subsection{Familia tradicional e preconceito}

A grande maioria vive em Famílias que são muito tradicionais e com uma cultura "naturalmente" mais preconceituosa, cuja visão e mente dos integrantes são mais fechadas. Podemos perceber em pais com idade mais avançada e alguns que fazem parte de grupos religiosos. Esses, tem um perfil não muito acolhedor ao que se trata de um membro próximo da Família fazer 
parte do LGBT. Por esse motivo o indivíduo sente-se acuado e não tem, muitas vezes, com quem contar ou se abrir, tendo ciência de que isso é fundamental nas relações humanas e saúde mental saudável.

Atualmente o conceito de Família vem sendo modificado, tendo como normalidade as novas composições, tais como um casal homossexual e filhos adotivos, assim como um casal de mulheres lésbicas e filhos adotados ou gerados por elas mesmas, uma mulher transsexual e um homem cis hetero entre diversas outras composições. O que para a comunidade é um grande avanço, poder formar suas Famílias da forma que melhor lhes compreende.

Trata-se de quem a pessoa verdadeiramente é, e a forma que ela ama uma outra pessoa não deveria ferir tanto o ego de seus familiares e pessoas próximas. Existem reportagens que mostram o quão o preconceito ainda é enraizado na mente do ser humano. Em que alguns dos entrevistados demonstravam de forma clara e pública sua preferência, caso fosse possível escolher, ter um filho ou parente próximo que fosse envolvido com o mundo do crime do que ser homossexual e repudiavam sequer imaginar ter em seu convívio familiar uma pessoa LGBT.

É através de pensamentos como esse que fazem com que essa comunidade seja uma Minoria sexual, termo que se refere a um grupo social cuja identidade de gênero, orientação sexual ou práticas sexuais que se diferem do restante da sociedade. Chega a ser assustador imaginar e ver com os próprios olhos que existem em pleno século atual pensamentos e posicionamentos tão retrógrados.

Não é necessário muito conhecimento para entender que as práticas homossexuais vêm desde a antiguidade, mesmo antes de Cristo como relata (Moreira Filho; Madrid, 2008), e faz outra observação acerca da naturalidade de relações homossexuais entre um jovem e um homem mais velho, contudo, as relações entre homens da mesma idade não tinham a mesma aceitação.

Em concordância com Costa e Nardi (2015), as práticas violentas existem devido as normas e padrões sociais que foram estabelecidos a muito tempo, que tem alicerce na heteronormatividade. Por meio disso, o LGBTQIA+ se torna frágil às vulnerabilidades, tanto fora quanto dentro de casa, que em alguns casos se torna o ambiente ao qual esses indivíduos mais sofrem hostilidades dos mais variados gêneros.

O gênero é uma complexidade em aberto (Tokuda, Peres e Andrêo, 2016, p. 923). Pode ser entendido como uma maneira inicial de produzir os sujeitos. Onde o molde de família retratado expõe que existe uma estrutura hierárquica, onde o homem está no topo como sendo uma figura viril e máscula caracterizando como pai, que tem como consequentes inferiores a ele, abaixo a esposa e os filhos que obrigatoriamente devem ter respeito e obediência ao esposo e pai que tem privilégios por ter um pênis.

Além de Braga, et al. (2018), conta-se com o raciocínio de Schulman (2010) que também expõe a ideia de que a forma como a família reage ao descobrimento da sexualidade de um membro do seu âmbito é de grande importância e fundamentalidade para a para a vida do sujeito. Pois é através disso que algumas ações e reações vão se objetivar, tal como a construção da identidade sexual dele.

\subsection{Fé, crenças, religião e inclusão}

O ser humano tem consigo bases que o acompanham desde seu nascimento, que percorre por toda a sua vida adulta. Todo indivíduo crê em algo, em alguma força superior e quando se trata do Brasil, um Estado Laico que é imparcial em relação às questões religiosas, dá o direito as pessoas escolherem as religiões que melhor lhes representa.

Quando falamos em religião, de forma cultural remete-se a igreja, um local onde busca-se acolhimento, paz de espírito e conforto. Durante muito tempo o público LGBT não foi bem-vindo, por vezes destratados e na pior delas expulsos dos templos religiosos que nada mais é do que celebrar as boas novas de Jesus Cristo. Essa realidade vem mudando com o passar do tempo. Para a surpresa e desgosto de muitos líderes religiosos e seus acompanhantes surgiram as chamadas "igrejas inclusivas", que tem 
por finalidade oferecer espaço para que este público possa vivenciar experiências de fé, e oportunidades de defenderem as bandeiras políticas e sociais do movimento nacional LGBT, como expõe (Barros, 2020).

Seguindo ainda, a linha de raciocínio de Barros (2020), pensar no comportamento homossexual como pecado, crime ou doença justifica, por vezes atitudes de repressão e violência. E são os movimentos sociais de gênero/LGBT que trazem à tona debates tão emponderados e enfrentamentos que transformam as sociedades aos quais estamos inseridos, colocando-as numa situação de sentir-se cobradas a rever seus conceitos e preconceitos, que são marcados no campo da moralidade e religião.

Entende-se desta forma a importância da inclusão, principalmente daqueles que estão em situação de vulnerabilidade e/ou minorias. Pois todos merecem ter a oportunidade de exercer sua fé com liberdade de expressão assim como todas as Famílias "tradicionais", e o que deve prevalecer sempre é o respeito para com todos.

\subsection{Resistência na busca por serviços de saúde}

Há resistência desse grupo no momento de procurar serviços de saúde, principalmente o público adolescente, afinal na maior parte das vezes se trata de jovens sem estrutura financeira. E necessitam buscar pelo SUS, que convenhamos é excelente. Mas por que resistência? Simplesmente por ter medo, vergonha, receio de como serão recebidos, ou por já terem vivenciado alguma experiência anterior negativa nos serviços que compreendem a saúde. E dessa forma dificulta para uma boa equipe de saúde realizar o acompanhamento desse indivíduo.

Como aponta Carvalho, et al. (2013), é de suma importância que os usuários dos serviços de saúde tenham conhecimento de seus direitos quanto cidadãos brasileiros para melhor exercê-los, pois são peças principais de vários movimentos, desta forma faz-se de extrema importância estar a par de alguns programas desenvolvidos, que lutam pelos direitos à igualdade dessa população. Afinal existem direitos, mas também deveres de ambas as partes, tanto do atendimento quanto do usuário, e ter ciência disso é algo extremamente relevante, ainda mais por se tratar de saúde, um fator principal e determinante na vida de um ser humano.

As doenças que mais acometem esse cliente/público infelizmente são de cúbito mental e Sexual, as Infecções Sexualmente Transmissíveis (IST), como aponta o Ministério da Saúde por meio do Plano Nacional de Enfrentamento de Aids e das DST (Brasil, 2008).

\subsection{Políticas públicas de saúde}

Um grande passo foi dado quando se instituiu a Política Nacional de Saúde Integral de lésbicas, gays, bissexuais, travestis e transexuais instituída pelo ministério da saúde em 2012, acredita-se que muito pode ser feito pela saúde, integridade e qualidade de vida desse grupo, que parte do conceito ampliado de saúde e do princípio da Organização Mundial da Saúde (OMS), que considera:

[...] a proteção do direito à livre orientação sexual e identidade de gênero não é apenas uma questão de segurança pública, mas envolve também, de maneira significativa, questões pertinentes à saúde mental e a atenção a outras vulnerabilidades atinentes a esses segmentos. (Brasil, 2008).

De acordo com estudos de base cientifica e interpessoal, entende-se que a educação, assim como a saúde é parte fundamental na criação de um cidadão de bem e saudável. Para representarmos a educação, segue a linha de raciocínio que diz que o homem é aquilo que a educação faz dele (Kant, 1803). E sobre a saúde, um marco importante foi uma conquista do movimento da Reforma Sanitária, que refletiu na criação do Sistema Único de Saúde, onde declara que: 
A saúde é direito de todos e dever do Estado, garantido mediante políticas sociais e econômicas que visem à redução do risco de doença e de outros agravos e ao acesso universal e igualitário às ações e serviços para a promoção, proteção e recuperação. (Federal, Constituição., Artigo 196.,1988)

Na data de 25 de março é comemorado o Dia Nacional do Orgulho gay e em 28 de junho o Dia Mundial do Orgulho LGBT. Tais datas comemorativas, passaram a existir depois de muita luta, para lembrá-los de que são importantes e que devem ter orgulho de quem são. Celebrar a luta por respeito e direitos igualitários. Trazendo isso para a vivência do cotidiano diário das equipes multidisciplinares em saúde, faz referência a algo que sempre foi questionado por eles: Por que não são tratados como seres humanos? afinal todos fazem parte de uma mesma sociedade.

Mais uma vez, de forma incansável deve-se haver treinamento periódico da equipe, para que possam ter experiência no atendimento de um homem gay, uma mulher lésbica, homem ou mulher transsexual e suas respectivas necessidades. Afinal cada um carrega consigo suas próprias especificidades e particularidades. Por vezes, um cliente ao buscar serviços de saúde, não precisa necessariamente de um procedimento da atenção terciária, mas sim da visão holística e atendimento humanizado da atenção primária. Dessa forma poderiam ser evitados inúmeros agravos à saúde dessa plateia.

\section{Conclusão}

O estudo evidencia um tema pouco discutido, e essa revisão, consequentemente trará benefícios extraordinários tanto para os atores principais desta história que é a comunidade LGBTQIA+ e a saúde deles, quanto para os profissionais de saúde que terão maior experiência no que diz respeito ao cuidado integral desse público em específico.

Sendo assim todo o contexto que rodeia a vida deste cliente ocasiona traumas muitas vezes irreversíveis, que andam com o indivíduo como cicatrizes pelo resto de suas vidas. Por meio de tal linha de raciocínio é necessário que a humanização no meio profissional, dando enfoque a Enfermagem seja presente em todos os níveis de atenção à saúde.

Destaca-se que por mais que a temática esteja em maior evidência atualmente, faz-se necessário aprimoramento quanto a estudos referentes ao tema de forma mais específica para que desta forma as equipes multidisciplinares possam ser conhecedoras das necessidades e demandas referente a esse público supracitado.

Que o presente possa ser de grande proveito, evidenciando o quanto viver de acordo com o nosso século é primordial. Estar devidamente atualizados sobre a vivência de uma nação para que a sociedade não faça parte de uma porcentagem que faz mal uns aos outros e sim que são benéficos, que contribuem para o bem de todos. Desta forma contribuindo para uma melhor qualidade de vida.

Pode-se afirmar que os objetivos propostos de forma inicial foram alcançados, foi possível dissertar sobre as questões de vida do grupo LGBTQIA+, tais como, a nível de conhecimento o significado da sigla, a violência para com eles, Família e preconceito, Fé e religião e políticas públicas de saúde.

Através da relevância de tudo o que foi discorrido durante este trabalho fica aqui exposto a sugestão de trabalhos futuros aos quais podem ser executados com uma grande chance de êxito, tais como, a realização de uma educação continuada, realizada por profissionais capacitados e que tenham a humanização correndo nas veias. Essa educação continuada deverá acompanhar a vida escolar de crianças e adolescente até chegar no nível acadêmico. A promoção de eventos e ações com iniciativa das equipes de saúde com a temática aqui exposta, para demonstrar apoio a comunidade e fazer com que esse grupo deixe de ser uma minoria vulnerável.

Ainda como sugestão, a composição e melhoria das Políticas de saúde que são voltadas a esses clientes. Pois suas composições são ótimas, mas que ainda podem ser aprimoradas, tornando-as excelentes

Após realizada leitura de um artigo cujo foco é a invisibilidade do LGBTQIA+. De forma harmônica com os autores de Souza Mandarino, et al. (2019), entende-se que o Programa de Pesquisa para o SUS (PPSUS), com foco na Política Nacional de 
Saúde Integral de Lésbicas, Gays, Bissexuais, Travestis e Transexuais (PNSILGBT) apresenta desorganização e ineficiência no que se trata de elaboração de políticas no enquadro saúde. Por tal, é crucial fazer com que na prática essas políticas e ainda programas, funcionem de forma ágil e prática.

\section{Referências}

Arán, M., Murta, D., \& Lionço, T. (2009). Transexualidade e saúde pública no Brasil. Ciência \& saúde coletiva, 14, $1141-1149$.

Barros, D.A.K. (2020). Igrejas “inclusivas” como espaços para a luta LGBT. Revista Vozes dos Vales. P. 1-18, 2020.

Barros, J. H. O., \& Coelho, G. G. (2021). Sobre (Vivências) Homossexuais E O Embate Familiar. Revista FAROL, 12(12), 23-40.

Braga, I. F., Oliveira, W. A. D., Silva, J. L. D., Mello, F. C. M. D., \& Silva, M. A. I. (2018). Violência familiar contra adolescentes e jovens gays e lésbicas: um estudo qualitativo. Revista Brasileira de Enfermagem, 71, 1220-1227.

Brasil, Ministério da saúde., Portaria $N^{o} 2.836$, de $1^{\circ}$ de dezembro de 2011. Institui, no âmbito do Sistema Único de Saúde (SUS), a Política Nacional de Saúde Integral de Lésbicas, Gays, Bissexuais, Travestis e Transexuais.

Brasil. (1988). Constituição da república federativa do Brasil. Brasília: Senado Federal, Centro Gráfico.

Brasil. (2008). Bissexuais, T. E. T Carta dos direitos dos usuários da saúde. Ministério da Saúde. Brasília.

Brasil. (2018). Sistema Único de Saúde.

Carvalho, L. S., \& Philippi, M. M. (2013). Percepção de lésbicas, gays e bissexuais em relação aos serviços de saúde- 10512/ucs. v11i2. 1837. Universitas: Ciências da Saúde, 11(2), 83-92.

Costa, Â. B., \& Nardi, H. C. (2015). Homofobia e preconceito contra diversidade sexual: debate conceitual. Temas em psicologia, $23(3), 715-726$.

De Souza Mandarino, A. C., Borges, W. C., da Silva Queirós, J., \& Gomberg, E. (2019). (In) visibilidades da saúde da população LGBT no Programa de Pesquisa para o SUS (PPSUS), Brasil. Revista Eletrônica de Comunicação, Informação e Inovação em Saúde, 13(3).

Ferreira, M. D. A. (2011). Enfermagem: arte e ciência do cuidado. Escola Anna Nery, 15(4), 664-666.

Fragoso, M. F., Meine, I. R., \& Carlesso, J. P. P. (2021). Prevalência De Casos De Violência Na População LGBTQIA+ No Contexto Intrafamiliar Em Tempos De Pandemia Da COVID-19. Revista Multidisciplinar em Saúde, 2(3), 15-15.

Grupo Gay da Bahia. (2018). Relatório 2018. Recuperado de https://homofobiamata.wordpress.com/homicidios-de-lgbt-no-brasil-em-2018/ Kant, Crítica da Razão Prática. Tradução de Artur Mourão. Lisboa: Edições 70, 1986. Ebook.

Moreira Filho, F. C., \& Madrid, D. M. (2008). A Homossexualidade e a sua história. ETIC-Encontro De Iniciação Científica, 4(4).

Peres, W. S. (2008). Travestis: corpo, cuidado de si e cidadania In: Fazendo Gênero 8: corpo, violência e poder. Florianópolis, $25,28$.

Schulman, S. (2010). Homofobia familiar: uma experiência em busca de reconhecimento. Bagoas-Estudos gays: gêneros e sexualidades, 4(05).

Silva, A. D. C. A. D., Alcântara, A. M., Oliveira, D. C. D., \& Signorelli, M. C. (2020). Implementação da Política Nacional de Saúde Integral de Lésbicas, Gays, Bissexuais, Travestis e Transexuais (PNSI LGBT) no Paraná, Brasil. Interface-Comunicação, Saúde, Educação, 24, e190568.

Tokuda, A. M. P., Peres, W. S., \& Andrêo, C. (2016). Família, gênero e emancipação psicossocial. Psicologia: Ciência e Profissão, $36,921-931$.

WORLD HEALTH ORGANIZATION (WHO). World Health Statistics (2018): Monitoring health for the SDGs. https://www.who.int/gho/publications/world_health_statistics/2018/en/. 